International Journal of Linguistics, Literature and Translation

ISSN: 2617-0299 (Online); ISSN: 2708-0099 (Print)

DOI: $10.32996 / \mathrm{ijlt}$

Journal Homepage: www.al-kindipublisher.com/index.php/ijllt

\title{
Challenges and Failures in the Contemporary Arab Discourse
}

\author{
Dr. Wafa Alkhatib ${ }^{\mathbf{1}}$ (D) $\triangle$ and Prof. Mohammad Al-Qudah ${ }^{\mathbf{2}}$ (ID) \\ ${ }^{7}$ Faculty of Arts, AL-Zaytoonah University, Amman, Jordan \\ ${ }^{2}$ Faculty of Arts, University of Jordan, Amman, Jordan
}

$\varangle$ Corresponding Author: Dr. Wafa Alkhatib, E-mail: wafakhatib@yahoo.com

\author{
ARTICLE INFORMATION \\ Received: May 26, 2021 \\ Accepted: June 25, 2021 \\ Volume: 4 \\ Issue: 6 \\ DOI: $10.32996 /$ ijllt.2021.4.6.23
}

\section{KEYWORDS}

Arab discourse, breakdowns, challenges, contemporary

\section{ABSTRACT}

This research deals with the challenges and defeats faced by the contemporary Arab discourse in all its forms and aspects, especially as it is experiencing a strong crisis between international and regional inconsistencies, produced by the forces of globalization and its uneasy pressures. Our basic thesis in this article can be summarized as follows. First, we argue that, can we say that the contemporary Arab discourse is dependent on the other, or is it a slave to the makers of globalization? Second, Does the Arab discourse in the present era issued by the same reference that was issued several decades ago, or is it reconsidering this reference to adapt to the circumstances and developments surrounding it? Or is it adapted between its Arab privacy, which starts from the constants and references that differ from our Arab reality and does not apply to our problems? To prove this, the article tries to shed the light on the credibility of the Arab political discourse, which constitutes a set of theoretical theses and hypothetical perceptions concerned with the author of the discourse only. It tries to reveal that the Arab political discourse does not touch the principle of practical application, as the recipients of political discourse feel disappointed and discredited because the author of the discourse derives his power from his authority and not from the authority of the masses, and loyalty is an absolute loyalty for him.

\section{Introduction}

Rhetoric means a system of regulated and controlled expression; while, the system in the term means the intellectual structure that holds a view, and from other definitions, it is the sum of the special expressions that are determined by their social functions and ideological project. Others define it as the way in which sentences form a sequential system which contributes to a heterogeneous and coherent macro-format; in such a way that the texts themselves may form in a sequential system to form a broader discourse involving more than one text. In this research the researchers will stop at the challenges and breakdowns faced by the contemporary Arab discourse in all its forms and colors; especially as it is living a clear crisis between international and regional contradictions produced by the forces of globalization and its pressures on the references of the Arab discourse.

This research deals with the challenges and defeats faced by the contemporary Arab discourse in all its forms and aspects, especially as it is experiencing a strong crisis between international and regional inconsistencies, produced by the forces of globalization and its uneasy pressures. This crisis has affected the authorities of the Arab discourse, plunged into its details, freedoms, statuses, values, specifics, and consonant, and introduced it into equations oscillating between a past full of ramifications, a present unaware of its focus, a dark future titled with confusion, alienation, and uncertainty, and uninterrupted questions arise from the surface to the depth from the far right to the far left and from the most specifics to the more generalities.

Therefore, the observer sees the challenges in it, as it is no longer that discourse that brings life to the organs of the Arab body. Of note, we do not find in it the rational discourse that discussed the other and persuaded him of his objectivity and significance.

\begin{tabular}{lll|l}
$\mathbf{K}$ & $\mathbf{C}$ & AL-KINDI CENTER \\
$\mathbf{R}$ & $\mathbf{D}$ & FOR RESEARCH AN
\end{tabular}

$\mathbf{R}$ D DEVELOPMENT

Your gateway to world-class research

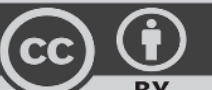

Published by Al-Kindi Center for Research and Development, London, United Kingdom. Copyright (c) the author(s). This open access article is distributed under a Creative Commons Attribution (CC-BY) 4.0 license 
Its intellectual structures are incapable of confronting globalization and its domination, as well as destroying the specifics of human beings that extend to the individual, demanding him to raise his hand in order to surrender. Therefore, legitimate resistance has become terrorism and accuses every dissident and opponent of being a vicious aggressor.

The contemporary Arab discourse has become dependent on the other and a slave to the makers of globalization, where the questions became its ideology and approach. So, does the Arab discourse in our time come from the same reference that produced it several decades ago, or is it starting to reconsider this reference to cope with the circumstances and developments surrounding it, or is it harmonizing between its Arab specificity, which starts from the constants and authorities and the premises of other authorities that differ from our Arab reality and do not apply to our problems (I).

Looking at this state of balance may qualify our contemporary Arab discourse to recommence with a better understanding of reality and the surrounding interests and policies that our discourse cannot disregard or overlook. Rather, it must engage in dialogue and debate and create an atmosphere of trust that will restore the presence and role of our Arab specifics, along with their interaction with its Arab surroundings and societies.

This research deals with the credibility of the Arab political discourse, which constitutes a set of theoretical theses and hypothetical perceptions concerned with the author of the discourse only. In other words, the Arab political discourse does not touch the principle of practical application, as the recipients of political discourse feel disappointed and discredited because the author of the discourse derives his power from his authority and not from the authority of the masses, and loyalty is an absolute loyalty for him. As for the state, it is absent because its political discourse is individual.

Reading the Arab reality shows the features of the suffocation in the contemporary Arab discourse, the discourse of disagreement and the mentality of treason in the discourse itself, along with the role of the Arab media in the embodiment of the awakening of reform, i.e. the reform of the entire discourse from a to z. Other than reforming the discourse, political, democratic, and cultural reform must be achieved through dialogue, reason and the Arab self and identity, preparing for the next relationship with the other to build a discourse capable of bridging the gaps among its people from the Atlantic Ocean to the Arab Gulf, and overcome the dilemmas and problems that led to the imbalance, separation, and division.

Thereafter, positive and negative facts are objectively placed before the nation and all concerned to re-create interaction and redirect energies to the elements of attraction, benevolence, and construction of Arab societies, in a way that serves the individual and his rights and benefits from the authorities of others without being drawn into discrepancies that serve the enemies of the nation.

It is necessary to read the facts more comprehensively within an intellectual framework based on the true value of man and the significance of the productive individual. Worth mentioning, this reading is based on the Creator and believing in Him and the righteous character and discipline that give everyone his rights, freedom, and status demanding him to do duties towards himself, his people, and society, alongside the active mind that thinks, plans and deals with issues with a broader and more general view stemming from the original inherent values, and looking at modernity with the same view in order to elevate man without affecting our intellectual, heritage and value authorities that have been able to influence the global discourse.

It is worth mentioning that our Arab discourse needs all constructive efforts of scholars, intellectuals and decision-makers, and our Arab media to restore the momentum and strength of our nation as a strong, effective, and leading nation able to map its reality and region in a more conscious manner than these lean years that have not produced anything in our reality yet. Instead of leading to prosperity, these lean years have led to a decline and neglect in our discourse in the corners of negligence and forgetfulness, as if we are a nation without identity, without resolution, without culture, thought or heritage, knowing that this nation does not lose elements of its roots throughout history only in these years when narrow interests exceeded all our political, economic, and cultural authorities.

\section{Crisis of the Cultural Discourse}

The cultural discourse is witnessing a clear crisis between the facts of the reality, the challenges of the future, the phenomenon of globalization, and the unilateralism that resulted in economic and political domination, leading to cultural domination in which the influence of our Arab-Islamic culture was absent. Cultural discourse has also become incapable of keeping pace with globalization, its manifestations, and information, communications, worldwide satellite networks. This domination led to the control of the public taste in food, clothing, and culture of consumption, and thus the spread of a popular culture unrelated to the culture of the elite and its data.

Consequently, a clear impact of the schools, universities, and educational and research institutions is no longer seen in changing the prevailing stereotypes in a cultural discourse based on inverted balances and conflicting concepts. 
Hence, the consequences of changing the historical role of the discourse were further civilizational fear and conflict, much debate about the end of history, distorting the image of Islam, and showing it as a source of violence and terrorism, as well as inaction, backwardness, misrepresentation of heritage and falsification of history, and globalization which does not want our discourse to apply science and technology and does not conform to any democratic choice that our peoples and nation produce.

Because of these results sweeping our culture, thought, and values and affecting our relations and human, it is necessary to return to our deep Arab-Islamic culture to strengthen and develop its components and apply technology scientifically and accurately, and eradicate necrotic diseases, whether in the duality of language or polar vision to form one vision based on continuation, persistence, accumulation, sound thinking, correct values and concepts that together form the basis of culture and its discourse. Moreover, language is the basis for understanding, education, and research, a framework for progress, production, and consolidation of identity. Otherwise, challenges will continue to hinder the cultural advancement that cultural discourse seeks (II).

Besides, the return to analyze, understood, and evaluate heritage is highly required to benefit from it in our modern life, and thus distinguishing it from others. Another task needed is to develop thought that suits our needs, institutions and theories, and the nature of our societies, and present it to new generations in a manner befitting the new rhythms that take the new generation to destinations and interests detached from their heritage and the mission of their nation in any way, as if our nation has no attitudes, no constants or no roots.

As a fact, this is the task of those responsible for this discourse to read the heritage carefully and assimilate it in a modern way to crystallize a comprehensive Arab cultural identity away from regional conflicts and narrow regional expressions because our cultural discourse was inclusive, comprehensive and purposeful and does not recognize the fragmentation and borders (III).

Overcoming the crisis of contemporary cultural discourse is contingent on diversity, vitality, difference, freedom and serious and fruitful understanding among the parties of the equation, extrapolating Arab Islamic thought and modernizing its tools and means, penetrating the other and accepting his/her culture and debating him/her consciously and openly through media that believes in the importance of cultural discourse and its role in building a system of awareness, pluralism, dialogue of cultures, and the spread a culture of tolerance, for example, Muslims in the past who have been a living example of tolerance.

With that, the cultural discourse must play its role in eradicating intolerance, imitation, and poverty in creativity, especially since several intellectual currents are still standing at the gates of the past and rush to retreat to a traditional past discourse incompatible with globalization and its sweeping trend. In other words, this role makes it imperative for the intellectual to have an independent spirit and leadership towards creativity, innovation, and achievement, investigate the truth that includes a critical vision preoccupying thought, not to shut up, weaken, and cry over the hard condition of the nation, as if it does not concern him because his thought and opinion are ignored by others, give emphasis to the importance of restoring self-confidence and authenticity on every occasion and interference, explore the reality of the danger posed to his nation, know how to deal with globalization, its technologies and means with openness and science, and reaffirm his commitment to the creative issues of man and the values of life in all their meanings, and thus create the conditions for revealing the potential of the human being from the realm of saying to the reality of life (III).

The contemporary challenges need to understand the present with its problems, creations, and challenges, the future with its ambiguity, successes, and horizons, and past with its manifestations and heritage, which forces us to face the internal challenges of superstition and absent mind as well as illiteracy, and the disintegration that affects the nation and its culture, and ways of thinking under different names and tendencies, i.e. ethnic, sectarian, regional, tribal, or clannish.

It seems that the manifestations of the new challenges are evident in the fragmentation, subversion, and destabilization of nationalities and the attempt to exhaust them and distort their languages and culture. As for the internal challenges, they are no less dangerous than the external challenges, which are represented in how to understand the Other's historical institutions and feelings towards Arabs and Muslims, and the style of discourse and the treatment that affects it, understanding of culture from the position of self-confidence, and a thorough understanding of the world in a unipolar system, as there are cultures and knowledge, rich and poor, and masters and slaves in the East and West, and how our situation looks in the light of the small global village, the concept of globalization, and the rise of individual interest on thought, culture, and knowledge.

So, there is a dire need to understand the culture of the West, especially the United States of America and its changing perception of our culture after $9 / 11$ attacks and the culture of violence that has become a major form of the contemporary challenges and the fall of the culture of Islamic tolerance. In this sense, do we remain silent in front of the Other's culture? Will alienation and powerlessness continue to control our culture? Or we must meet the challenges rationally and objectively and search for a location for ourselves and our nation without fear, helplessness or inaction. It is worth mentioning that our nation 
has been and continues to be appreciated in its rationality, thought, civilization and the efforts of its scientists, as the goal that everyone seeks is to reach a pure, gorgeous, and new image of our Arab-Islamic culture, and to be free, open, authentic and confident. As a result, do we need to re-read our heritage and history? Do we need to consider deeply how the world deals with us, and are we preparing for an ambiguous future we do not know what will bring to us?

What we are looking for is a conscious reading from a holistic culture that is fit for society and all people; a culture that does not know racism, does not embrace narrow tribalism or inactiveness, ready to coexist with other cultures, take advantage, reject disadvantage, and encourage the intellectual to build a mind to accommodate the movements of liberation, reform and enlightenment heritage in human civilizations that adopt a critical approach to enable it to play its role in the contemporary Arab discourse.

Therefore, we do not want our nation to be on the sidelines, but play its active role because our culture is the cause of each of us, and that universities shall have their projects and plans to examine the reasons for the decline seen in the Arab reality, and have a major role in the elimination of division and underdevelopment and fight all forms of cultural decline. More importantly,

With that, intellectuals should activate their role through the initiative in investigating the human issues, the intellectual structure and the civilizational experience of our nation, presenting their ideas clearly and boldly without damaging their platforms, make their ideas an extension of their words and actions, be advocates of authenticity and commitment, achieve a creative and innovative culture, avoid leaving the young generation as victims to fashion, satellite channels and sandwich culture, take their hands and raise their importance and capabilities to be in the forefront, and not allowing the challenges to weaken our task or impede our efforts because of the several obstacles and challenges facing us today, but our ambitions and potential are great, and all we have to do is to contemplate our reality deeply and seriously to know where the is the end, and this is not done without real consciousness experienced by our nation.

\section{Awareness Discourse}

When some intellectuals and writers demanded and wrote about the return of consciousness, they were aware of the nation's ignorance, suffering, weakness, and fragmentation, especially in the wake of the June 1967 Setback, demanding the Arab nation to return to its mind, rationality, and unity so that this violent setback would not push our nation into loss, disintegration, disruption and anxiety with unhappy ends.

When we look at the general atmosphere dominating the Arab street at that time we do not see it far from the current general atmosphere. With that, will the nation have to ruminate about its wounds, pain, and conditions of existence? Or should life be breathed in? The priorities are for intellectuals and thinkers to play this role as the current situations grind the whole Arab body; these thinkers and intellectuals should lead the Arabs to extrapolate lessons, return to consciousness, and think carefully and deeply about the past with its achievements and legacy.

The Arabs today face a new reality that necessitates them to unite and forget their wounds, differences, ethnicities, ethnology, and ideologies for the future of their nation and their people. It is a future that must be far from the furnace of the occupation, which does not respect the feelings of anyone, neither in Iraq nor in Palestine, and this calls us as Arabs to eliminate ill ideas, rise from the wounds, and give up our differences and powerlessness.

The consciousness's return must urge us to think and disbelieve the media, its satellites, its fabricated news, its repeated abuses, and lack of respect for the feelings of our nation. The Arabs are required to work day and night to shape their conditions and circumstances instead of feeling stunned and shocked that Baghdad and Iraq are under occupation, and Jerusalem and Palestine are being destroyed under their eyes as if they do not concern them. Notably, let us confess the bitter reality that Iraq today, which is in the third millennium, is under occupation based on baseless justifications and we find no one to object or condemn, and if there are objections, they are weak and shy because the criticism of the occupation is considered atheism and is not permissible under the law of the jungle. For instance we have seen how the occupation transmits news and threatens satellite channels so as not to bring the truth to the people, and how it destroys the truth by killing reporters, where more than seventy journalists have been killed in Iraq since the occupation so far, as the Arabs in general and Iraqi in particular must mainly take care of this. Moreover, we should not believe the conspirators' arguments that the Iraqi people are divided into different sects where throughout our lives, we do not know that there is a difference between Shiites and Sunnis, but they are the productions of the occupation, which wants each brother to kill his brother to build his bases and loot his wealth after the occupation destroyed the whole structure and awarded tenders to its companies. Arabs and Iraqis must regain consciousness and endure each other to consolidate and restore the Arab, Islamic, and international face, value, and status to the Arabs.

The discourse of consciousness must affect our acts, minds, souls, emotions, and hearts, which is a necessity to defend our honor, dignity, and humanity because its absence means surrender, loss, submission, acceptance of the status quo. Furthermore, 
it is considered a deep sleep and weakness, applause for the occupation and the joy of its coming for occupying our land and honor under the baseless names and charges, as well as the continuous promotion of imposing of democracy on the Arab regimes and compelling them to carry out democratic reforms that they are themselves do not apply in the sites that they reach or occupy, and unfortunately that its democratic occupation has resulted in terrorism, misery, frustration, poverty, extremism, alongside unbearable tyranny.

The Iraqi people in particular, in all its categories and sects, and the Arab world, in general, need to be aware because the chapters and the drama of the reality are in front of everyone's eyes, and this must stimulate and push the Arab system to take its share of the future blessings of democracy, which is knocking on our doors morning and evening. In fact, the Arab system also should not disregard these facts and adhere to the power and the temptation of wealth because all that we have recently seen is the path to the tragic end for the Arabs, and a profit for Israel, which today seems comfortable with what happened to Iraq and the Arabs. Of note, Israel is currently entering the line of Iraq through the various doors because it considers itself the actual partner of the United States of America with a priority more than other occupiers in looting the wealth of Iraq to implement the plans that have long dreamed of for decades.

The current situation, its requirements, its premises, and its developments require us to think rationally about how to reform ourselves and our democracy to achieve justice, equality, pluralism, and accepting the other opinion, whatever it may be, to keep the other voice from resorting to the arms of our enemies. For example, we have seen how the opposition returned to Iraq on the front sight of freedom rifles, which calls for everyone to take this lesson, comprehend the opposition and hear its voice and take its opinion if it is constructive and useful, and our nation finds this challenge easy to deal with, but uneasy about overcoming. Importantly, the discourse of awareness is subject to acceptance of the other to face the stormy challenges that threaten us to avoid the upcoming tempests in the future. Thus, let our minds, our sects and societies think freely about the fundamental issues we need, because the Arab nation is in a state of weight loss and is in grave danger after seeing the chapters of the occupation of Iraq, and this call for awareness is a call for dialogue, life, freedom, and creativity.

\section{Stimulating the Discourse of Consciousness or Legitimizing Violence?}

Various questions arise in the Arab world on activating awareness and knowledge and their role in renewing Arab life, changing patterns and consolidating understanding and methods of dialogue on a well-organized and well-defined style. When we contemplate what is going on around us from the challenges, propositions, and concerns, we wonder why consciousness is absent or who makes it absent and in the interest of whom? Is it based on conviction or are the cultural, cognitive and intellectual structure immersed in theorizing, and thus unable to perform its role so that it no longer distinguishes its ideas from its duties and rights? Has society reached a state in which the logic of reason is absent to the extent of dependence on the unknown? This is really a general condition that has appeared in several societies.

Faced with this situation, let us ask about the reasons that legitimized violence and terrorism and tried to find justifications and pretexts for them. Is it the new American legitimacy? Are they new terms with their irrational labels? Is it democracy and its terms of interest or the absence of real democracy? Are these the reasons behind this flood of free killings that hits everywhere? Is it the product of what the Western and Zionist media broadcast on a daily basis, where the Arab media are repeating the terms without realizing that they are actively involved in the legalization of these terms? Note that our fellow men are relentlessly killed in its name, and does not this event represent a clear case in which the mind and consciousness are absent?

These terms include, for example, the absence of a Palestinian partner to sit and discuss with him, and the term of the right of self-defense as there are daily countless massacres under this hollow slogan, which has become a lie through which all kinds of oppression are practiced. Terrorism, which turned the resistance of oppressed peoples into terrorist peoples and attempts to market it to the United States of America, the world and the Arab world, has been a success that led to the destruction of the world and its stability and turned it into tense spots. Unfortunately, this has made human beings' only concern on the ground is to fight the so-called terrorism and thus making several armed organizations and groups legitimately defend their interests against the so-called war on terror.

We must consider how the whole world was before 9/11, and how it became after this date leading to ask the following "Is the world in consciousness or consciousness was absent as a result of being driven by hollow terms in which the target party does not emerge? The United States cannot be cleared of the criminal attempts, violence, and chaos that it has created for itself and for the region as a whole. For example, Iraq is the witness and martyr of the real absence of reason and the replacement of consciousness by murder and destruction. Besides, wounded Palestine lives on inverted terms and justifications and evasions that have led to a real daily disaster for the Palestinian people in the eyes of the Arab and humanitarian worlds.

In the face of these bitter disasters, is the terror of fanatics, extremists and desperate people different from the role of professional tyrants who are in uniform and kill in cold blood? Aren't all of them involved in disrespecting human life? Does 
market fundamentalism, which destroys the world for its own interests and tramples on human dignity and rights, differs from religious fundamentalism that rejects the achievements of market fundamentalism? Doesn't this fundamentalism produce a blind curtain that leads to the rule of irrationality? Doesn't the US arrogance and its contempt for human beings and the appointment of itself the world's policeman make it monopolize legitimate violence and thus the use of weapons whenever you want and without the authorization of anyone? Don't these policies, which are protected under the guise of globalization and closed dogmatism, lead to the disruption and rebellion of the peoples and turn them into submissive consumers who have no mind and no consciousness? All this has led to the transition from the virtue of goodness, peace, freedom, and harmony to the legitimization of evil, violence, and murder.

Policymakers, who have been able to perpetuate a culture of violence, crime, war, and devastation after mixing up the cards and opening the world to uncertain future prospects and repercussions, are paying the price for this. Isn't consciousness the first victim? Isn't terrorism in its nomenclature and terminology the first responsible for this devastation, which shatters the values, virtue, and understanding, and confines human beings in the requirements of the discourse of death and war and put them in descriptions and mixtures with the inability to distinguish the advocate of peace from the advocate of destruction? They no longer know whether this is an advocate of human rights, a cleric, a general or a lute player. Accordingly, we ask the following: How long will the absence of consciousness continue? Why are the rights of thinking and expression absent? And who benefits from fighting creativity, stability, and human security? Why is the culture of fear prevalent among human beings at a time when the scales are overturned so that grave mistakes and their practice are acceptable in a world that does not try to punish the perpetrators? Why is the world conspiring against its stability, nation, consciousness, and value system?

It is necessary to renew awareness and build a knowledge system that does not overlook the multiple and contemporary humanitarian systems, identify reality and its crises, revive the knowledge society and expand its base to say neither to violence, its justifications, its legitimacy, nor to the inverted terminologies and slogans that are launched via media and used daily in programs and meetings that hide catastrophes, problems, and pain. The knowledge society should also say no for the discourse of estrangement as if we were a nation unrelated to the other and the generation of pioneers, alongside the mentality of treason that does not recognize the importance of consciousness, or the ideas of hatred played by some intellectuals haunted by the concerns of the Holocaust, blood, and the radical discourse leading to the making of orders and selecting a path based on ambiguity and illusions, and violence.

Radwan Ziadeh, a Syrian academic and executive director of the Syrian Center for Political and Strategic Studies in Washington and a visiting researcher at the Care Center for Human Rights at Harvard University, said that our nation does not have a serious realistic discourse that examines the mechanisms of Arab backwardness and the ways in which we explore the future renaissance prospects. Ziadeh adds "And yet what to do now? Do we wait or move to restore life to the exhausted Arab individual through a clear media discourse that restores the individual's balance and makes him feel the justice of his cause and freedom?"

\section{The Religious Discourse}

The religious discourse's renewal in its cultural structure and components has become an important necessity in light of developments in the media, and when we stop at our contemporary discourse, we recognize the imbalance faced by our religious discourse and its inability to develop, compete and persuade, especially since the means of persuasion are still limited to hearing without sight, which is something other cultures relied on to conquer the world and reach advanced levels that affected the system of values and ethics in the entire Muslim world, especially the Arabs. Regrettably, we still care for the preacher's garment more than his role and importance; a preacher who affects his audiences and recipients for only a few minutes after he finishes his sermon. The sermon is not a whip to lash the listeners, but it must provide the Muslim with piousness and compassion, though it shall be accompanied by a renewal in the discourse, approach, faces, alongside visions and choices that do not change with time. For example, our religious programs still pose superficial issues and guidance that focus mainly on shallow principles, and the most substantial thing is to get to the depth in order to get rid of the dilemma that this Muslim has not yet known how to do ablution or prostrate, or kneel, and this is evidenced by the Prophetic Hadith, which has been narrated on the authority of Umar b. al-Khattab that the Messenger of Allah (PBUH) said: (The value of an action depends on the intention behind it. A man will be rewarded only for what he intended. The emigration of one who emigrates for the sake of Allah and His Messenger (PBUH) is for the sake of Allah and His Messenger and the emigration of one who emigrates for gaining a worldly advantage or for marrying a woman is for what he has emigrated. What is more, it is not permissible to stop long on the form of the Muslim and the way of worship, but what is required is to open the doors to profound and important issues of interest to the whole nation and clarify the image of Islam and its role in building a civilized valuable system recognized by the world as it recognized its justice, seriousness, viability, and tolerance in the past. Thus, where are we from the problems of the nation? Why is the focus on dialogue programs and doctrinal issues affirmed in all sources of Islamic religion and legislation? 
Why are weakness, boredom, and laziness caused by the discourse of these programs? And why is the only focus on one presenter?

It is also saddening that some of the presenters do not renew his readings and ideas and cannot attract the public because of the weakness of his discourse and his inability to capture the concerns of the Muslim and the attitude of the world towards him, his Islamic beliefs and religion alike, bearing in mind that Islam is a religion capable of keeping pace with the times and its challenges, and our Holy Quran and the teachings of our religion are valid everywhere and time, but unfortunately, conditions and times are changing and our discourse is still static and unchanged and does not change, although it is capable of developing, updating, changing, and reforming at all times.

Islamic discourse is every body's responsibility, especially scholars and Da'wa men, who must change the garments of seclusion in the Mosque and judging people with atheism to the garments of religion and the world. Transferring the discourse from the ebb stage to the flow stage which convinces the other through a mass media discourse that guarantees the ability to criticize and accept the other opinion, even if that opinion is unfair because the message of Islam and its discourse were based on persuasive evidence. Therefore, it is necessary to renew the religious discourse and develop real strategies developed by scholars, intellectuals, and professors of information, social, psychology, economics and Sharia because they are better able to distinguish and judge the change and renewal and develop programs with clear messages to introduce the other to the truth and moderation of Islam.

Islam and its moderation are compatible with developments in the world, speak different languages and address different trends in a way that fascinates and entices viewers and audiences away from exaggeration, extremism, and judging people with atheism to change his misunderstanding about Islam and Muslims. The renewal of religious discourse is not only limited to the media and religious programs, but also from the home, family, school, and university, and the faculties of Da'wa and Sharia cannot remain closed to new ideas that push forward and defend Islam, as it should not remain as a taboo for new generations to engage in its dialogue and debate and the audacity of putting it as if it is a violation of the teachings of Islam, and therefore an opposition against the opinion of the Islamic group. For those who say that Islam belongs to one sect without another or group without another, it should be noted that Islam is the religion of all featured by its comprehensiveness, awareness, strength, moderation, and reasonableness. The faculties of Da'wa and Sharia must move to consolidate contemporary Islamic concepts that are commensurate with globalization and foreign cultures so that Islam does not remain captive and abducted to groups that do not have a voice other than their voice and do not accept an opinion other than their own.

Accordingly, we are required to return to the voice of reason, the authenticity of Islam and its delight, and the image of Islam which treated all peoples with love, respect, and peace to restore the Islam's presence, rationality, discourse, image, veneration, and its role in the cultural dialogue.

\section{The Religious Discourse}

The media discourse is at the heart of the communication and connection process, deals with reality with its challenges, circumstances, and ideas, and communicates with the other and convinces us that we are a nation with an important civilizational message that has unrepeatably been damaged by the internal discourse and then taken and conveyed by the external discourse with new interpretations that led to negative images. Accordingly, what media discourse can enhance the negative image of the Arab and Muslim in the West, which is a distorted and unclear image that hates the West because of religious intolerance as if the entire discourse of Muslims is the discourse adopted by Osama bin Laden!

George Corm, a Lebanese economist and Middle East specialist, attributed the reasons for distorting the image of the Arabs to two reasons. First, their military incompetence, inability, and failure to fight back any attack in their recent history as he believes that in the new international order, any people must have the elements of self-defence to win the respect of the other. Second, their economic deficit, which is another reason for the negative image, especially when they are compared with South Korea, Malaysia, Singapore, and China on the one hand, when they were poorer countries than the Arab countries, and how they have attained an economic and political position in the global economic system, while the Arab countries remained consuming countries with no interest in production, along with the Arabs' inability to form a consistent and firm Arab group that adopts consistent and solid positions within the framework of the international system, and the image we see is still full of divisions and separation among Arabs.

In order to succeed in addressing the West, we have to reconsider the arrangement of the Arab house in a clear order based on firm positions, adopting legitimate and convincing methods, which take democracy as a real goal away from uncertainty, failure, and the practice of intellectual and cultural repression, and then we may define the contours of our influential and contemporary media discourse in changing the image of Arabs among the others. 
Therefore, Arab thinkers and scholars focus on some issues to determine the nature of the media discourse and its principles in front of the discourse of the other and its media machine that feeds negative images and convey the facts that do not change even if times and the means of communication change.

The Arabs are one nation that has the right to life, its civilization, its cultural identity, its unique position, its comprehensive religion that unites races and minorities and rejects murder and intimidation.

Therefore, we must define our positions on terrorism and do not work on a double standard rule, like the other works on a clear double standard. We also must continue to define the concept of terrorism and distinguish it from legitimate resistance, as the Arabs are exposed to terrorism more than others because they are not of its structure and basis, and their issues are just and do not deserve a unipolar bias against it. No matter where they come from, all mass media must act to expose terrorist practices with the ongoing assurance that the distinction between legitimate resistance and terrorism is a necessity. The former is a legitimate right of the occupied peoples, and the second is unacceptable because it kills people in cold blood without reason or guilt, and what we see today is the result of the economic and political conditions that have marginalized the Arab image.

Therefore, there must be a media discourse based on a convincing political discourse in which the individual knows his position and attitude, launches his vision freely and respectfully, and understands that his rights and practice of democracy and pluralism are a normal matter, and therefore the transfer of power is smoothly done. What is more is that the media discourse convinces the other that the Arab individual possesses himself, his power, thought, and value system, noting that the media campaigners against Arabs and Muslims are not left with the opportunity to continue to inject negative images that increase fanatics and extremists on the other side because the Arab citizen can no longer improve his image and change its black pattern.

The media discourse needs clear, effective, honest, and frank language that expresses the truthfulness of our issues and the humanity of our human being. When some of us ask: Who are we, where are we, what do we want and in what language do we address the other? We have to answer honestly and openly that we are a nation with a mission to look for factors of stability, success, and joy from within. In detail, we are a nation living in a changing world that must know how to address and deal with the other, and what we want is what any individual who wants, we want to live in safety, freedom, and respect, and respect the other as we respect him/her, and these questions are inseparable from what we have mentioned above about the reasons for distorting our image.

Our Arabic language, which has absorbed the achievements of the ages and successive times, deserves to remain strong, effective, and influential away from the image written by French journalist Paul Balta, when he said: "Since the beginning of the Algerian War in 1954 and the Suez Campaign in 1956, the image reflected by the Europeans about the Arabs is generally confined to the following formulas: the terrorist, whether Mujahid (Muslim Fighter), Fedaye (Commando) or kidnapped, the poor migrant worker, the unqualified ignorant, the Gulf rich man that emerged in the wake of the emergence of oil, and the fanatic fundamentalist that emerged after the Khomeini Revolution in 1979. It is the same image that the West still broadcasts daily in all its media messages, which is still stuck in their minds".

Therefore, it is necessary to change and replace this overall image and its partial images with new realities and dialogue that reflects our rebellion against all these images; an equal dialogue among equal parties. It is well known that the equal dialogue is not accepted between the strong and the weak because it reflects the relationship of the master and the slave and is incompatible with the conditions of dialogue in a living language that fixes our image and defines our civilization, our values and our, a language that perpetuates and reinforces the language of discourse, defines the objective and does not retreat, and convinces the other that we have the required elements and means away from the language of violence. This is not done without a variety of media means that speak to the other in their language and textual and audiovisual means, conferences, symposiums and exhibitions that can access the depths of the other to remove the accumulated fabrications, lies and distortion.

III-advisedly, today, the Arab media discourse is scattered, and each state has its means and methods and does not live up to persuasion, but is governed by instant emotions and moment, and we must remember how propaganda and public relations agencies are able to enlarge our issues, provoke Western public opinion, and promote the war against our nation. Today, our media discourse should strongly go through its experiences inside and outside the Arab world through a language that meets the renewed needs of the recipients, and not to be lost because of the means of fascination from his right way to correctly start reform and develop.

\section{Conclusion}

In a nutshell, there is a dire need to address the others through a well-defined and clear media and religious discourse that aims to change the distorted image and perceptions in the minds of others in general and the West in particular. Our Arab media discourse should strongly work on revealing the real nature of our Arab Muslim identity through a modern language that can meet the new events and concepts in our real-life situations. 
Therefore, we are in need of a logical media discourse, one that does not provoke compassion and does not plead with the other to persuade it, a discourse that opens horizons with a scientific framework and objective analysis that the other recognizes and puts it in parallel with his discourse, which is not impossible for a nation that possessed a civilization recognized by the world when it was paralleled by power, science, and thought. Today, our media discourse should strongly go through its experiences inside and outside the Arab world through a language that meets the renewed needs of the recipients and not to be lost because of the means of fascination from his right way to correctly start reform and develop

\section{References}

[1] Abaad Magazine, where to start? Fares Abu Saab, The Lebanese Center for Studies, Beirut, May, 1994, pp. 2-5.

[2] Analysis of the Arabic Discourse: Selected Research, 1st Edition, Philadelphi University Press, Amman 1997, p. 110

[3] "Al-Rai" newspaper, in the contemporary Arab discourse, d. Muhammad Al-Qudah, Amman-Jordan, January 26, 2006.

[4] Al-Rai Newspaper, The Crisis of Cultural Discourse, Dr. Muhammad Al-Qudah, Amman-Jordan, 2/2/2006, looking at Ahmad Bahaa Al-Din's book "Intellectuals and Power in Our Arab World", Kuwait, October 1999.

[5] "Al-Rai" newspaper: activating awareness or legitimizing terrorism, d. Muhammad Al-Qudah, Amman-Jordan, May 6, 2004.

[6] Al-Rai Newspaper, Religious Discourse in Media Programs, Dr. Muhammad Al-Qudah, Amman-Jordan, 2/25/2006.

[7] The Arab Discourse: Content and Style, Arab Thought Forum, 1st Edition, Amman-Jordan, 2003, p. 45.

[8] Al-Rai Newspaper, Communication and Communication between the Media Discourse, Dr. Muhammad Al-Qudah, February 16, 2006, and see the Arabic Discourse in Content and Style.

[9] Ibid., Pp. 80-85.

[10] Al-Qadiri, A. (1995). Islam and the Clash of Civilizations, The Ummah Book, 1st Edition

[11] Muslims and the Age, Al-Arabi Book, Kuwait, 1987

[12] Arabic Discourse Analysis: Selected Researches, previous reference, pp. 107-120.

[13] "Al-Rai" newspaper, unity is a utopia and a utopia, d. Muhammad Al-Qudah, Amman-Jordan, 9/30/1995.

[14] "Al-Rai" newspaper, Al-Arab and the Next Century, d. Muhammad Al-Qudah, Amman-Jordan, 4/21/1997.

[15] "Al-Rai" newspaper, a bright spot, d. Muhammad Al-Qudah, Amman-Jordan, 5/7/1999.

[16] "Al-Rai" newspaper, Al-Qahbi Al-Arabi, d. Muhammad Al-Qudah, Amman-Jordan, 10/16/1998.

[17] "Al-Rai" newspaper, preparing for the twenty-first century, d. Muhammad Al-Qudah, Amman-Jordan, 1/7/2005.

[18] Ibid.

[19] "Al-Rai" newspaper, Al-Arab and Al-Mustaqbal, d. Muhammad Al-Qudah, Amman-Jordan, 3/24/2005.

[20] "Al-Rai" newspaper, unity is a utopia and a utopia, d. Muhammad Al-Qudah, Amman-Jordan, 9/30/1995.

[21] "Al-Rai" newspaper, Al-Arab and the Next Century, d. Muhammad Al-Qudah, Amman-Jordan, 4/21/1997.

[22] "Al-Rai" newspaper, a bright spot, d. Muhammad Al-Qudah, Amman-Jordan, 5/7/1999.

[23] "Al-Rai" newspaper, Al-Qahbi Al-Arabi, d. Muhammad Al-Qudah, Amman-Jordan, 10/16/1998.

[24] "Al-Rai" newspaper, preparing for the twenty-first century, d. Muhammad Al-Qudah, Amman-Jordan, 1/7/2005.

[25] Ibid.

[26] "Al-Rai" newspaper, Al-Arab and Al-Mustaqbal, d. Muhammad Al-Qudah, Amman-Jordan, 3/24/2005

[27] Mahmoud Al-Sharif, The Arabs and the Future: Intellectual Approaches, Amman, 2005.

[28] Mahmoud Al-Sharif, The Arabs and the Future: Intellectual Approaches, Amman, 2005.

[29] Michel Foucault, "The Excavations of Knowledge", 1st Edition, translated by Samer Leghouth, The Cultural Center, Casablanca, 1987, pg. 34

[30] Muhammad Abed Al-Jabri, The Contemporary Arab Discourse, Edition 2, Dar Al-Taleea'a, Beirut, p. 128.

[31] Mahmoud Al-Sharif, The Arabs and the Future: / Intellectual Approaches, Amman, 2005

[32] Said Maaloush, Dictionary of Contemporary Literary Terms, Casablanca 1985, p.83

[33] The cultural magazine, about the full report of Penerman between acceptance and rejection, Dr. Suhaila Al-Rimawi, The University of Jordan, Amman, No. 9 1985/1986, pp. 96-97

[34] The Editorial Journal of Culture "Yes to Activate the Energy of Awareness", Dr. Muhammad Al-Qudah, Issue 64/65, University of Jordan, Amman, Jordan, 2005, pp. 5-7

[35] The Arab Discourse: Content and Style, The Arab Thought Forum, 1st Edition, Amman - Jordan, 2003, p. 45.

[36] Symposium on Democracy and Political Reform in the Arab World, the concept of political reform in some texts of the neo-liberal Arab discourse, Dr. Omaima Abboud, Cairo University, 2005.

[37] Final report on the Petra Retreat, titled "Content of Arab Discourse and Style", Jordan, 5/4/2002

[38] Diwan Obaid bin Al-Abras

[39] Diwan Ibn Zaidoun.

[40] Ghusayb, H. (2005). The Arab Intellectual Discourse and the Challenges of Modernity, Manuscript Research, Princess Sumaya University, Amman - Jordan

[41] Turki, A. (2001). Trial and Terrorism: The Mentality of Treason in Contemporary Arab Discourse, 1st Edition, Dar Al-Rayyes, Beirut.

[42] Radwan, Z. (2001). The Ideology of the Renaissance in Contemporary Arab Discourse, 5th Edition, 2001. 